\title{
INTERCOSMOLOGIAS: HUMANOS E OUTROS MAIS QUE HUMANOS NO NORDESTE INDÍGENA
}

LEANDRO DURAZZO ${ }^{1}$

UFRN, BRASIL

https://orcid.org/0000-0001-5160-2835

JEAN SEGATA ${ }^{2}$

UFRGS, BRASIL

https://orcid.org/0000-0002-2544-0745

RESUMO: Um conjunto amplo de trabalhos que intersectam os campos da etnologia indígena $e$ das relações humano-animal tem produzido importantes debates na antropologia contemporânea. No Brasil, sobremaneira, o debate se concentra sobre material empírico amazônico com o qual se tensionam ontologia e epistemologia com o questionamento dos limites do humano em relação a outros seres e modos como se organizam em mundos. Neste trabalho, iniciamos uma reflexão a partir de pesquisa sobre o Nordeste indígena e de como aspectos destacados de suas sócio-cosmologias - a fluxos, trocas e contatos ontológicos - nos levam a pensar em uma rede de trocas complexas e multidirecionais que poderia apresentar uma "nova cartografia social" indígena onde figura, também, de modo mais ou menos consciente, uma nova cosmografia social que complexifica e expande o campo das relações entre humanos e outros mais que humanos na antropologia.

PALAVRAS-CHAVE: Intercosmologias, Nordeste indigena, Humanos e mais que humanos.

ABSTRACT: A wide range of works intersecting the fields of indigenous ethnology and humananimal relations have produced important debates on contemporary anthropology. In Brazil, the debate mainly focuses on empirical Amazonian material with which ontology and epistemology are strained with the questioning of the limits of the human in relation to other beings and the way they organize themselves in worlds. In this work, we started a reflection based on research on the indigenous of Northeast Brazil and on how outstanding aspects of their socio-cosmologies - flows, exchanges and ontological contacts - lead us to think about a complex and multidirectional exchange network that could present a "new indigenous social cartography" which also features, more or less consciously, a new social cosmography that complexifies and expands the field of relations between humans and others more than humans in anthropology.

KEYWORDS: Intercosmologies, Northeast indigenous, Humans and more than humans.

\footnotetext{
1 Doutor em Antropologia Social pela Universidade Federal do Rio Grande do Norte. E-mail: leandrodurazzo@gmail.com

${ }^{2}$ Professor Adjunto do Departamento de Antropologia da Universidade Federal do Rio Grande do Sul, atuando também no Programa de Pós-Graduação em Antropologia Social e no Programa de Pós-Graduação em Políticas Públicas. E-mail: jeansegata@ufrgs.br
} 


\section{Introdução}

Em um dos seus mais conhecidos textos, Eduardo Viveiros de Castro (1996) recorre a Lévi-Strauss para sublinhar o que extensos dados etnográficos têm registrado desde há muito na história da antropologia: a "grande difusão de auto-etnônimos cujo significado é 'os humanos verdadeiros" (Viveiros de Castro, 1996, p. 123). O autor prossegue discorrendo sobre a noção de etnocentrismo, mas podemos desde já restringir nosso foco. Ao lançar mão da referência às muitas categorias nativas - dos muitos povos indígenas/originários encontrados ao longo da história e do planeta - Viveiros de Castro (1996) indica em sua tradução um tema em que nos deteremos. As terminologias nativas segundo as quais "a humanidade cessa nas fronteiras do grupo" (Viveiros de Castro, 1996, p. 123; cf. também Barth, 1969), traduzível ao português e demais línguas modernas - e ocidentais - por "humanos verdadeiros", desde o princípio estabelecem uma diferenciação ontológica clara, fundamental, e que as próprias considerações do autor virão a desenvolver.

Tanto Viveiros de Castro quanto Philippe Descola, apenas para citar dois dos nomes envolvidos com a temática, insistirão na gradação nãodualista que nossa perspectiva ontológica ocidental tende a ignorar. Segundo Descola (1998, p. 25), "as cosmologias amazônicas estabelecem uma diferença de grau, não de natureza, entre os homens, as plantas e os animais". Isso significaria dizer, através de um perspectivismo dialógico entre categorias nativas e antropológicas - também na esteira de um "descentramento das filosofias da consciência"3 - que não apenas o ponto etnocêntrico dos "humanos verdadeiros" teria autonomia ontológica, inclusive autorreflexiva, mas que variados estratos daquilo que podemos chamar de realidade - outros domínios biológicos, mas também geográficos e cosmológicos - formariam uma complexa teia de relações, sociais.

A ênfase nas relações, portanto, mais do que em seus elementos dispersos e identificáveis, é preocupação tanto de Viveiros de Castro quanto de Philippe Descola. Este último, em particular, ao esquematizar processos mais específicos dentro do quadro geral de uma continuidade ontológica de graus variados - algo como o perspectivismo ameríndio baseado em certa gradação multinaturalista - propõe três termos operativos. Para ele, as relações sócio-cosmológicas poderiam se dar por reciprocidade, predação e dádiva (Descola, 1998, p. 27). A compreensão não-dualista de um universo ontológico, desse modo, acarretaria posturas e ações diferenciadas entre si - como os termos operativos

\footnotetext{
${ }^{3}$ Movimento de descentramento das filosofias da consciência: "não que morte da subjetividade, mas morte do sujeito identificado com a máscara voluntarista de um ego forte [...], levanta a questão dessa subjetividade como 'portadora' [...] de estruturas inconscientes e espirituais (ou imaginais), fato que, por um lado, reduz a subjetividade como consciência-máscara voluntarista mas, pela mesma movência, amplia a 'subjetividade' enquanto portadora de um 'destino' [...] que não é 'fado', mas sim realização de uma 'totalidade abrangente'.” (Paula Carvalho, 1998, p.109); ainda, alguma modalidade do que Johannes Fabian (1991, p. 199) chamou de "apprehension of otherness which is possible only through negation of self and same".
} 
indicam - de modo que o perspectivismo ameríndio não constituiria automaticamente um par opositor em um binarismo etnocentrismo/perspectivismo. Desse modo, seria também possível contornarmos a dicotomização ontologizante ou seja, deixar de lado uma necessidade - da lógica ocidental - em categorizar relações binárias e contraditórias (o terceiro-excluído na lógica de Aristóteles) para dar conta da compreensão de análises sociais.

Voltaremos à importância das categorias ontologizantes (porque em processo de constituição, não como dados ontológicos estáveis) ao fim deste texto. Por ora, basta que mantenhamos em mente que os "sistemas de relações mais particularizados", como Descola (1998) os chama, "correspondem a três modalidades lógicas e também sociológicas de integrar a oposição universal entre eu e outrem". O autor continua:

A reciprocidade quer que toda vida animal seja compensada (frequentemente por uma ou outra forma de vitalidade humana); a predação implica que nenhuma contrapartida seja oferecida pelos humanos contra uma vida animal; finalmente, a dádiva significa que os animais oferecem sua vida aos humanos de maneira deliberada e sem nada esperar em troca (Descola, 1998, p. 37).

Veremos que os usos e práticas sociais - e por sociais também entenderemos cosmológicas - variam grandemente, sempre de forma correlacionada às distintas disposições socioculturais dos povos considerados. O próprio Descola (1998) contextualiza, indicando um modelo ilustrativo da categoria reciprocidade entre os Desana, povo de língua tukano do noroeste amazônico; também faz a indicação da predação entre os Jivaro, além dos Aruaque como exemplares do sistema de dádiva. Em nosso caso, analisaremos alguns modelos de relações cosmológicas entre povos indígenas do Nordeste brasileiro, buscando apontar outras dinâmicas sociais que também relativizem - e flexibilizem - nosso modelo lógico ocidental de binarismos opositores e excludentes.

Antes de passarmos a isso, cabe lembrar a sutileza presente na distinção terminológica que Bruno Latour (2014), falando sobre outra maneira de compor o mundo, oferece a nossos propósitos. Tratando de viradas ontológicas, o autor também vai indicar - como Descola pouco acima - a imprecisão das dicotomias mantidas pelos estudos ocidentais desde há muito. Assim, sugere que as abordagens fenomenológicas em filosofia, por exemplo, quando projetadas para compreender outros universos humanos, não-ocidentais, constituíam uma dicotomia subjacente. Entre a ontologia lógica ocidental, por exemplo, e o entendimento de cosmologias outras, a validação destas últimas só poderia ser realizada através da categorização em "abordagens fenomenológicas", destituindo-as de toda legitimidade própria. Outros modos de conhecimento - e vida humana, e organização social etc. tomados enquanto polos opostos ao conhecimento legítimo ocidental, seriam acessíveis apenas através dessa "falsa dicotomia" (Latour, 2014, 
p. 303), isto é, apenas por meio de uma absorção pelos próprios termos ocidentais. O autor vai indicar, entretanto, que tomadas em suas realidades imediatas - como nos casos etnográficos em que o antropólogo teria menos possibilidade de negar a realidade presente de seu campo e interlocutores - tais ontologias nativas poderiam deixar de ser tratadas tão-somente como "ontologias nativas", já que possuem em si mesmas as bases, inclusive lógicas, de sua legitimidade. Ontologias nativas, perspectivismos, relações sócio-cosmológicas - cosmopolíticas, Latour (2014) vai recordar, seguindo Isabelle Stengers - desse modo, abririam caminho para nossa compreensão, aceitação e conhecimento de, poderíamos dizer, outras epistemologias.

\section{Sócio-cosmologias no Nordeste indígena}

Os povos indígenas do Nordeste, sobretudo durante o século $X X$, em contato com instituições tutelares e movimentos por reafirmação étnica e conquista de direitos sociais passaram por muitas e diferentes articulações no que diz respeito às suas próprias autodefinições. Desde as organizações dos "remanescentes de índios" reivindicando reconhecimento do Estado (Oliveira, 1999) até a centralidade do toré como elemento diacrítico de etnicidade (Grünewald, 2005), muitos elementos culturais foram dinamizados não apenas no seio dos diferentes povos, mas nas redes de contato e troca entre eles. José Maurício Arruti (1999), por exemplo, ao estudar o caso do povo Atikum, menciona que sua emergência na década de 1940 se deu "em consequência de seu contato com os Tuxá", povo oficialmente reconhecido desde muito antes (Arruti, 1999, p. 9). As redes de troca, política mas também cosmopolítica - se pensarmos o papel do toré e de outros rituais nesse processo - permitiram um grande movimento de emergências étnicas e reavivamentos de elementos simbólicos, antes atribuídos aos "caboclos", mas lentamente identificados como efetivamente indígenas (não é à toa que Rodrigo de Azeredo Grünewald intitula o volume que organiza, em 2005, de "Toré: regime encantado do índio do Nordeste"). Neste texto, nosso olhar se deterá sobre as múltiplas dimensões que o regime encantado do toré, mas também o regime dos encantos e encantados, oferece como base de entendimento epistemológico.

De modo resumido, tem-se que os encantos - também chamados encantados, no que parece ser uma posição intercambiável de nomenclaturas - são entidades sobrenaturais, mas vivas, que chamamos mais-que-humanas por seu estatuto diferencial frente aos humanos viventes (cf. Alarcon, 2013 para os Tupinambá; Cardoso, 2018, p. 408 para os Pataxó; Durazzo, 2019, p. 163 para os Tuxá), que estabelecem um vínculo direto e colaborativo com as comunidades indígenas vínculos acionados através de diversos procedimentos e observâncias rituais. À diferença dos espíritos dos finados, muito presentes em diversas religiosidades espiritualistas, os encantos podem ser tanto antepassados que se encantaram - não tendo morrido, portanto, mas 
passado a um diferente estrato cosmológico - quanto entidades diretamente relacionadas à natureza, como a Mãe d'Água e a Dona da Mata, por exemplo, entre os Atikum (Léo Neto, 2012, p. 56, nota 14).

É válido notar, desde já, que as categorias com que o discurso indígena opera tendem a separar, ainda que sutilmente, os domínios da natureza de outros mais humanos, como na distinção entre encantados. Entretanto, na maior parte dos casos não parece haver uma dicotomia radical, dado ser possível a transição entre ambos os domínios, em certas circunstâncias. Ainda assim, tomada a realidade indígena do Nordeste, com seu longo histórico de contato e participação na sociedade nacional, não admira que uma lógica dicotômica potencialmente ocidental esteja presente em seus quadros epistêmicos. Note-se, quanto a isso, a inclusão de entidades judaico-cristãs em seus panteões, se assim podemos chamálos. Clarissa Lima, falando de sua experiência entre os Xukuru da Vila de Cimbres, diz: "Todas as perguntas que eu fazia a respeito dos demais seres que habitam o cosmos, este ponto era enfatizado, fossem santos, espíritos, encantos, pessoas [...] primeiro de tudo, Deus." (2013, p.166). Também para os Tuxá de Rodelas/BA e de Pirapora/MG, dentre muitos outros grupos indígenas, há uma relação compósita entre mestres encantados e divindades cristãs. Como diz o pajé tuxá Armando Apako: "sabido é Jesus, a Virgem Maria, o divino Pai Eterno e o Espírito Santo, e nossos mestre" (apud Durazzo, 2019, p. 255). Os humanos, segundo o pajé, não passariam de carne podre, não tendo sabedoria apenas por si, senão por sua relação de trabalho na ciência, como é conhecido o complexo sócio-ritual de grande parte dos indígenas no Nordeste (Durazzo, 2019).

As relações cosmológicas indígenas apresentam uma série de elementos naturais, para além dos encantos: entre os Xukuru do Ororubá, é notável a litolatria que mantêm com diversos pontos de sua terra, como demonstrou Rita Neves (2005). Ainda na dimensão geológica dos simbolismos indígenas, poderíamos mencionar a relação íntima que povos como os Pankararu, Kambiwá, Truká, dentre outros, estabelecem com o que Wallace Barbosa (2003) chamou de "pedra do encanto": a "semente da aldeia", que funda sua legitimidade enquanto espaço étnico - mas também "semente mestre", para o levantamento de cada praiá, esta "podendo ser uma pedra, ou um fóssil, ou ainda uma cerâmica" (Mura, 2012 , p.159). É curioso notar como a relação semente/pedra (ou semente/fóssil, ainda semente/cerâmica) nos dá elementos terminológicos para conectar, de modo metafórico, diferentes domínios da realidade: mineral, vegetal, animal, técnico; "referências cosmológicas importantes", no dizer de Edmundo Pereira sobre seu registro fonográfico dos toantes Kapinawá, povo onde também encontramos tais relações entre domínios (Pereira, 2005 p. 312).

Também alguns encantados possuem nomes referentes a um domínio geológico, como Seu Monte Só (Pankararu e Kariri-Xocó, cf. Barbosa, 2003, p. 170). A dimensão mineral dos simbolismos indígenas no Nordeste ainda serve como artifício de manejo mágico-religioso, como sabemos ao conhecer a história de um mestre Truká que seria capaz, no caso de um encanto ou mesmo de um espírito forçando entrada em um 
ritual ou se comportando de modo inconveniente, mandar seus "espíritos protetores pegarem este elemento e o prender bem no meio do rio, dentro de uma pedra, de modo que ele não vai mais poder chegar no [...] trabalho" (Batista, 2005, p. 92).

Mas é com os domínios vegetal e animal, sobretudo, que os simbolismos acionados pelo ritual indígena encontram sua maior força e profusão. Se ainda mantivermos nossa atenção nos nomes ostentados por alguns dos encantos mais conhecidos, teremos uma clara noção desse entrecruzamento: Vim-Vim, Jataí e Seu Beija-fulô entre os Kambiwá ("tem que batizar com o nome dos pássaros”, cf. Barbosa, 2003, p. 169); Sultão das Matas, Papagaio Amarelo, Boi do Corte, Rei Porquinho, a Sereia entre os Kiriri (além da descrição física dos encantos como bravios, de olhos esbugalhados e ferozes - quase animalescos, cf. Nascimento, 2005, p. 44, para os Kiriri, e Durazzo, 2019, p. 146-ss, para os Tuxá); Mãe d'Água e Dona do Mato ou Caiporinha, entre os Atikum, além de Mestre Tubarãozim e Mestre Tubibano (que seria "dono de todas as abelhas, governando-as e sendo o 'Rei das Matas'”, cf. Léo Neto, 2012, p. 57).

Ainda no domínio apícula dos Atikum, temos algumas formações geográficas nomeadas segundo abelhas, como as serras do Arapuá e a da Tiúba - esta, nome de uma abelha, mas também de uma "cabocla" que teria vivido na região (Léo Neto, 2012, p. 56, nota 15). Encontramos a importância simbólica das abelhas também entre os Kapinawá, em seus sambas de coco que servem para "cantar a abelha e o fazer mel" (Pereira, 2005 , p. 313). Neste sentido, vale notar tanto para os Kapinawá quanto para os Atikum algo que Edmundo Pereira evidencia ao dizer que "Grünewald (comunicação pessoal, 2004) informa que a abelha em seu fazer o mel pode ser também considerada como algo da ordem do sagrado, uma vez ser atividade relacionada aos encantados" (Pereira, 2005:324).

Sobre as performances rituais Pankararu hoje, sabemos que durante as "corridas do umbu, ritual ligado à fertilidade da terra" (Acselrad et al, 2005:287), praiás dançam noites inteiras "numa sequência coreográfica e gestual em que são representados movimentos de animais: a abelha, o boi, o cachorro, o urubu, o peixe, entre outros" (Acselrad et al, 2005, p. 288). Os autores ainda marcam a presença animal em outra expressão relativa a tal período ritual: a Noite dos Passos, em que a palavra "passos" é, provavelmente, "corruptela de 'pássaros', como é comum na pronúncia da região" (Acselrad et al, 2005, p. 287).

Retomando a nomenclatura Kambiwá, é interessante saber que "Entre os pássaros relacionados como passíveis de serem identificados aos encantos, estão o vim-vim, a andorinha, o beija-flor, o papagaio, o ararão e a asa-branca, mas só existem sementes disponíveis para os dois primeiros" (Barbosa, 2003, p. 169). Por tais afirmações somos capazes de evidenciar, cremos, a importância do processo de constituição dos encantos - como no "levantamento de encantados" de que fala Claudia Mura (2012) - pois torna-se evidente a dimensão relacional entre entidades cosmológicas, por um lado, e processos sociais ativos e atuantes, por outro. Ou seja, independentemente da existência potencial de encantos e demais seres, sua atualização se torna possível apenas por 
meio da atuação indígena, relacionando seus respectivos povos (já que cada encanto estabelece vínculos étnicos específicos) às sementes que os podem levantar.

Evidente também é a dimensão conflitiva e tensional que muitas vezes envolve tais processos. Não apenas os encantos com nomes de animais possuem uma relação direta com esses domínios, mas mesmo outras entidades nomeadas dinamizam a convivência indígena com os poderes sobrenaturais da natureza. Ainda com Wallace Barbosa, sabemos que a época de levantamento da aldeia Kambiwá assistiu ao desenrolar de alguns atritos entre especialistas da tradição ritual. O autor nos informa sobre uma "discussão dentro da ciência" que teria ocorrido quando o pajé João Tomaz, Pankararu que auxiliava no reaprendizado ritual dos Kambiwá, confrontou o então responsável pela tarefa, Zé Índio, considerado um "xangozeiro" (e aqui ficará ainda mais explícita a distinção fundamental entre regime de índio, com toré e encantos, e regime alheio, com espíritos de mortos, xangôs, tradições afrobrasileiras, entre outras). Luís Pereira, interlocutor de Wallace Barbosa, diz que Zé Índio "amarrou o dono do mato no pé do cruzeiro. A gente chamava as forças das matas e não vinha porque "tava amarrada!" (Barbosa, 2003, p.181). Na segunda metade dos anos 1970, o mesmo Zé Índio auxiliaria o povo Kapinawá a (re) fundar uma legítima "tradição indígena" demonstrando a condição fluida e contextual de tais acionamentos étnico-rituais (Albuquerque, 2008, p. 57). Sobre este personagem, ainda, Albuquerque nos informa pertencer ao povo Xucuru (2005, p. 258), o que ampliaria ainda mais o mapa étnico dos contatos aqui delineados.

\section{Fluxos, trocas e contatos ontológicos}

Podemos pensar, na sequência dos dados expostos, que o que chamamos - conscientemente - de condições "sobrenaturais da natureza" não se configura, necessariamente, nem como uma dicotomia excludente (sobrenatural ou natural), nem como paradoxo irreconciliável (nos mesmos termos opositivos). Antes, apelando a uma desconstrução lógica, valorizando o oxímoro complementar mais do que o paradoxo estrito (Paula Carvalho, 1990, p. 218), talvez chegássemos perto de apontar o que Lévi-Strauss, respondendo a Eduardo Viveiros de Castro em 1998, chamou de sobrenatureza. Lévi-Strauss diz que

A representação da [ciência] física parece muito mais, no fundo, com o que no caso indígena chamaríamos uma sobrenatureza. Nós consideramos que o mundo da física é mais verdadeiro que o mundo da experiência, mas ao mesmo tempo admitimos que não compreendemos nada dele. Nosso mundo físico é nossa sobrenatureza. (Viveiros de Castro, 1998, p.126) 
Acessadas por expedientes rituais, determinados dons e ciências dos índios, as esferas ontológicas que vimos tratando não parecem ser instâncias estanques no pensamento ameríndio do Nordeste. Ainda que não acessível imediatamente à experiência, ainda que não acessível a todos, o que tratamos como diferentes estratos cosmológicos ainda assim permite um trânsito fértil e constante entre seus elementos - e assim retornamos à importância da relação como categoria analítica. Como dizem Maria Rosario de Carvalho e Edwin Reesink (2018), pensando os povos do Nordeste:

a literatura comprova que mais de 450 anos de genocídios e etnocídios, no âmbito do regime de relação assimétrica, resultaram em povos indígenas que aprenderam a persistir em esferas socioculturais próprias, ocultando-as o máximo possível aos olhos dos dominantes, em particular na esfera social compartilhada com os últimos e em que esses outros exercem seu domínio. (Carvalho, Reesink, 2018, p. 94).

Duas considerações podem reforçar o entendimento relacional desses diversos níveis cosmológicos. A primeira se refere à heterogeneidade do que, sob nossa própria perspectiva, poderia surgir como um polo indistinto, homogêneo e genérico dos "reinos dos encantados". Somos confrontados com uma noção de cosmologia variada, em que os encantos não estão na natureza acessível a nossos sentidos, mas tampouco em dimensões etéreas e "espirituais". Para os Truká, "A Mãe D’água vive num castelo invisível - aos nossos olhos - no fundo do rio, e possui muitas riquezas, podendo se agradar de algum mortal e levá-lo (encantá-lo) para junto de si" (Batista, 2005, p. 89). Tal especificidade possui distinções não apenas ontológicas, mas também étnicas, já que nas ilhas do rio São Francisco, por exemplo, "a junção de terra e água favorece as correntes da água, que são as protetoras do grupo Truká. [...] Em oposição ao grupo Atikum, por exemplo, que é da Serra Umã (município de Carnaubeira da Penha, Pernambuco) que encontra sua força nas correntes da mata" (Batista, 2005, p. 93). Ainda do ponto de vista étnico, diacrítico mesmo, temos que

Os Atikum diferenciam "encantados da terra" e os "encantados do ar" (ou "encantados de luz") [...] Quando a conexão com o mundo místico é estabelecida através da ingestão da jurema e do ritual do toré, abrese um canal através do qual determinadas pessoas com a capacidade mediúnica irão incorporar (ou como eles dizem, "enramar" ou "manifestar"). (Léo Neto, 2012, p. 57)

Também entre os Kapinawá e os Truká, mas não apenas, temos a ideia de "enramar" e "irradiar" a presença dos encantos. Entre os Tuxá, fala-se do mesmo modo que "estão mais ligados aos encantados do rio", dentre os quais está seu protetor, Seu Ká-neném. O relato sobre este 
encanto, inclusive, demonstra a dinâmica quase completa de fluxos, trocas e relações que aqui tentamos descrever. Veja-se, por exemplo, a descrição que dele temos no trabalho de Elisabeth Nasser:

\begin{abstract}
Esse encantado, como todos os outros, pode tomar as mais diversas formas; animal e humana. Nesta última ele tem a faculdade de apresentar-se como velho, rapaz ou criança, dependendo da hora do dia, noite, tarde e manhã. Poucas pessoas têm o privilégio de vê-lo. Sua aparição é mais habitual durante a realização do [ritual] particular, quando os participantes encontram-se sob o efeito tóxico da jurema, beberagem feita com a casca da raiz da juremeira preta (Mimisa nigra Hub). Os outros encantados também possuem o poder da corporificação antropomorfa e zoomorfa, porém o Velho Ká-neném é o único que alia a aparência humana à idade biológica, na dependência da hora do dia em que é visto. (Nasser, 1975, p. 127).
\end{abstract}

Encantado e humano (e, podemos dizer, animal, além do que não classificamos), Seu Ká-neném é uma boa representação das modulações ontológicas das quais tratamos aqui. Ademais, vale ressaltarmos sua característica específica: sendo o único encantado capaz de aliar aparência humana ao período do dia correspondente, Seu Ká-neném coloca as instâncias de apresentação humana/animal atreladas a outra ainda, qual seja, a dos ciclos cósmicos e rítmicos concernentes ao correr do dia (dos astros e, por extensão, do tempo). E, nisso, podemos arriscar uma consideração quase estrutural entre a passagem do dia e a transição entre vida e morte dos humanos viventes: alguns Tuxá de Rodelas relatam que, antigamente, os índios tornavam-se capivara ao morrer e se encantar - isto é, não morrer efetivamente, senão passar a um estatuto ontológico de maestria, podendo ser mestres encantados desse ponto em diante (cf. Durazzo, 2019:157; também Cardoso, 2018:176-180 para os Pataxó). Assim, se o encantado Ká-neném ajusta sua manifestação humana de acordo com o período do dia em que ela ocorre, há relatos de viventes que, encantando-se, podem mesmo assumir formas não-humanas para manifestar sua mais-que-humanidade.

Não apenas os encantos têm a capacidade de transitar entre os mundos, mas também aqueles humanos envolvidos no ritual podem, em dadas condições, caminhar em diferentes instâncias cosmológicas, sobretudo quando servindo de vínculo ritual entre estas. Por exemplo, um mestre Truká "do Particular nos disse que todas as vezes que um encanto vem, a pessoa que está cedendo o seu corpo, ao abandoná-lo, se retira e vai para o "reino dos encantados'" (Batista, 2005, p. 93). Há discordâncias entre a retenção ou não das memórias referentes a tal reino, já que se recomenda ao "viajante" a manutenção de certo sigilo sobre o assunto, mas Mércia Batista conta que, em conversas informais e discretas, foi informada que "muitos lembram dessa experiência e são capazes de descrever o 'reino dos encantados', que é situado no fundo 
do rio e possui tudo aquilo que o mundo cotidiano possui, com a grande diferença dada pela riqueza e pela permanência" (2005, p. 93).

É aqui, talvez, que a segunda consideração pode nos auxiliar a encerrar este texto. Ainda que muitos elementos naturais não-humanos possam ser mobilizados no regime encantado do índio do Nordeste quais sejam, sobrenaturais, animais, geológicos, diversos níveis cosmológicos, etc. - também é possível encontrarmos uma fundamentação cultural de seu amplo espectro cosmológico. Se no perspectivismo amazônico é possível pensar uma única condição cultural primeira, da qual os "humanos verdadeiros" seriam expoentes máximos - sob nosso ponto de vista - em algumas descrições do regime do índio do Nordeste, regime encantado, tal cultura humana básica também se apresenta. E aqui, ainda, sobreposta a uma dimensão utópica evidente: o reino dos encantados pode ser descrito como um lugar de "riqueza" e "permanência".

Mas o mesmo movimento que re-ontologiza a humanidade, inserindo-a no coração do complexo cosmológico dos encantados, também conduz algumas coletividades indígenas a rearticularem seu discurso étnico de acordo com um diálogo potencialmente não-indígena. É desse modo, por exemplo, que acreditamos poder enxergar na categoria nativa Xukuru "mata sagrada", para além de uma consideração indígena integrada ao entorno e à terra, um elemento epistemológico outro, que não nativo. Segundo Descola (1998), para outros contextos geo- e etnográficos, é possível dizer que

Muitas organizações ecológicas, aliás, encontram uma fonte de inspiração nas visões de mundo dos índios da Amazônia ou da América do Norte, convertidos pela mídia em símbolos da convivência harmoniosa com uma natureza cada vez mais ameaçada. A "mãe-terra" ou a "floresta sagrada" tornam-se conceitos genéricos da sabedoria étnica, mas seria bem difícil encontrar seu equivalente exato na maior parte dos povos a quem se atribui esse tipo de noção, pois tais transposições em mão dupla não estão livres de quiproquó: frequentemente, a retórica ecológica de alguns líderes indígenas exprime menos as concepções cosmológicas tradicionais - complexas e diversificadas, logo difíceis de formular no código simplificador de nossa economia política da natureza - do que um desejo de obter o apoio de organizações internacionais influentes, graças a um discurso facilmente reconhecível, e com a finalidade de conduzir lutas de reivindicação territorial (Descola 1985; Albert 1993). De selvagens, espera-se que tenham a linguagem de filhos da natureza; como eles deixariam de fazê-lo se, por aí, podem precaver-se da espoliação fundiária? (Descola, 1998, p. 24)

Certamente necessitamos de ainda muitos estudos e dados etnográficos para correlacionar a noção de "mata sagrada" às de "mãe- 
terra" e "floresta sagrada", que Descola (1998) aponta. Entretanto, a quase inexistência desta formulação - desta fórmula linguística - em outros povos do Nordeste que não os Xukuru pode dar elementos para cogitar tal hipótese. Também é certo que nenhum diálogo interétnico, por assim dizer, informado ou enformado por organizações ecológicas, tem sua validade dialógica e seu potencial político deslegitimados - muito pelo contrário, se pensarmos no retorno do nativo de que nos fala Adam Kuper (2002). Mas é curioso percebermos como, no seio de "complexas e diversificadas" concepções cosmológicas, diversos elementos de outras cosmologias - cosmopolíticas, portanto, epistemologias - parecem encontrar espaço e acolhida.

Este contato interétnico, por fim, talvez nos auxilie a não considerar apenas a dicotomia ontológica clássica no Ocidente, o binômio invariável que já foi grande divisor da antropologia - em suas modalidades nós/eles, natureza/cultura, natureza/sobrenatural, entre outras - mas tampouco assumir como chave explicativa uma suposta sobrenatureza ontológica outra, sem considerar os processos pelos quais as cosmologias vão, pouco a pouco, se constituindo. Processos epistemológicos, como já indicava Elisabeth Nasser em 1975, mas também como agora em 2012 foi enunciado pelos Xukuru redatores de uma "Nova Cartografia Social". Estudando a sociedade Tuxá, Nasser identificou na presença da escola regular uma ameaça potencial às heranças e tradições nativas, pelos conflitos interétnicos a que os jovens seriam submetidos quando frequentando o universo escolar não-indígena. Por outro lado, os Xukuru hoje nos informam que "A escola [indígena] ajuda a trabalhar a tradição. Ela ensina o jovem a respeitar e acreditar na natureza. É preciso fazer o trabalho de conscientizar. É um mistério!" (Almeida, 2012, p. 4).

Há, nessa contraposição de proposições, um sinal de diferentes posturas e contextos sociais, é certo, mas também de distintos modos de articulação de conhecimentos. O que tentamos delinear aqui, brevemente, foi a possibilidade dos processos dinâmicos e das relações - interétnicas, mas também intercosmológicas, se quisermos propor uma nova terminologia - que mobilizam elementos sociais e simbólicos dos povos indígenas do Nordeste em constante diálogo com demais repertórios sociais. É por meio dessa rede de trocas complexas e multidirecionais, acreditamos, que se pode apresentar uma "nova cartografia social" indígena onde figura, também, de modo mais ou menos consciente, uma nova cosmografia social que complexifica e expande o campo das relações entre humanos e outros mais que humanos na antropologia. 
Espaço Ameríndio

\section{Referências bibliográficas}

ACSELRAD, Maria; VILAR, Gustavo; SANDRONI, Carlos. Torés Pankarru ontem e hoje. In: GRÜNEWALD, Rodrigo de Azeredo. Toré: regime encantado do índio do Nordeste. Recife: Fundaj: Editora Massangana, 2005, 283-297.

ALARCON, Daniela Fernandes. A forma retomada: contribuições para o estudo das retomadas de terras, a partir do caso Tupinambá da Serra do Padeiro. RURIS, volume 7, número 1, p. 99-126, Mar. 2013.

ALBUQUERQUE, Marcos Alexandre dos S. O torécoco (o forgar lúdico dos índios Kapinawá da Mina Grande - PE). In: GRÜNEWALD, Rodrigo de Azeredo. Toré: regime encantado do índio do Nordeste. Recife: Fundaj: Editora Massangana, 2005, 257-282.

. O dom e a tradição Kapinawá (ensaio sobre uma noção nativa de autoria). Religião e Sociedade, Rio de Janeiro, 28(2): 2008, 56-79.

ALMEIDA, Alfredo Wagner Breno de. [et al.] Nova Cartografia Social dos Povos e Comunidades Tradicionais do Brasil: Xukuru do Ororubá - PE. Manaus: UEA Edições, 2012.

ARRUTI, José Maurício. A árvore Pankararu: fluxos e metáforas da emergência étnica no sertão do São Francisco. In: OLIVEIRA, João Pacheco de. A viagem da volta: etnicidade, política e reelaboração cultural no Nordeste indígena. Rio de Janeiro: Contra Capa, 1999, 229-278.

BARBOSA, Wallace de. Pedra do Encanto: dilemas culturais e disputas políticas entre os Kambiwá e os Pipipã. Rio de Janeiro: Editora Contra Capa, 2003.

BARTH, Fredrik. Ethnic groups and boundaries: the social organisation of culture difference. Bergen: Universitetsforlaget; London: Allen \& Unwin, 1969.

BATISTA, Mércia Rejane. O toré e a ciência Truká. In: GRÜNEWALD, Rodrigo de Azeredo. Toré: regime encantado do índio do Nordeste. Recife: Fundaj: Editora Massangana, 2005, 71-98.

CARDOSO, Thiago Mota. Paisagens em transe: ecologia da vida e cosmopolítica Pataxó no Monte Pascoal. Brasília: IEB Mil Folhas, 2018.

CARVALHO, Maria Rosário de; REESINK, Edwin B. Uma etnologia no Nordeste brasileiro: balanço parcial sobre territorialidades e identificações. BIB - Revista Brasileira de Informação Bibliográfica em Ciências Sociais. São Paulo, n. 87, p. 71-104, 3/2018.

DESCOLA, Phillipe. Estrutura ou sentimento: a relação com o animal na Amazônia. Mana 4 (1): 23-45, 1998.

DURAZZO, Leandro. Cosmopolíticas Tuxá: conhecimentos, ritual e educação a partir da autodemarcação de Dzorobabé. Tese (Doutorado) - Centro de Ciências Humanas, 
Espaço Ameríndio

Letras e Artes, Programa de Pós-graduação em Antropologia Social, Universidade Federal do Rio Grande do Norte, 2019.

FABIAN, Johannes. Time and the work of anthropology: critical essays, 1971-1991. Amsterdam: Harwood Academic Publishers, 1991.

GRÜNEWALD, Rodrigo de Azeredo. Toré: regime encantado do índio do Nordeste. Recife: Fundaj: Editora Massangana, 2005.

KUPER, Adam. O retorno do nativo. Horizontes Antropológicos, Porto Alegre, ano 8, n. 17, p. 213-237, junho de 2002.

LATOUR, Bruno. Another way to compose the common world. Hau: Journal of Ethnographic Theory, 4 (1): 301-307, 2014.

LÉO NETO, Nivaldo Aureliano; GRÜNEWALD, Rodrigo de Azeredo. "Lá no meu reinado eu só como é mel": dinâmica cosmológica entre os índios Atikum, PE. Tellus, ano 12, n. 22, jan./jun., 49-80, 2012.

LIMA, Clarissa. Corpos abertos: sobre enfeites e objetos na Vila de Cimbres (T.I. Xukuru do Ororubá). Dissertação de mestrado. São Carlos: UFSCar, 2013.

MURA, Claudia. "Todo mistério tem dono!": ritual, política e tradição de conhecimento entre os Pankararu. Tese de doutorado. Rio de Janeiro: Museu Nacional/UFRJ, 2012.

NASCIMENTO, Marco Tromboni de S. Toré Kiriri: o sagrado e o étnico na reorganização coletiva de um povo. In: GRÜNEWALD, Rodrigo de Azeredo. Toré: regime encantado do índio do Nordeste. Recife: Fundaj: Editora Massangana, 2005, 3970.

NASSER, Elizabeth Mafra Cabral. Sociedade Tuxá. Dissertação de mestrado. Salvador: UFBA, 1975.

NEVES, Rita de Cássia Maria. Dramas e performances: o processo de reelaboração étnica Xukuru nos rituais, festas e conflitos. Tese de doutorado. Florianópolis: UFSC, 2005.

OLIVEIRA, João Pacheco de. A viagem da volta: etnicidade, política e reelaboração cultural no Nordeste indígena. Rio de Janeiro: Contra Capa, 1999.

PAULA CARVALHO, José Carlos de. Antropologia das organizações e educação: um ensaio holonômico. Rio de Janeiro, Imago,1990.

Imaginário e metodologia: hermenêutica dos símbolos e estórias de vida. Londrina: Ed. UEL, 1998.

PEREIRA, Edmundo. Benditos, toantes e sambas de coco: notas para uma antropologia da música entre os Kapinawá de Mina Grande. In: GRÜNEWALD, Rodrigo de Azeredo. Toré: regime encantado do índio do Nordeste. Recife: Fundaj: Editora Massangana, 2005, 299-328. 
VIVEIROS DE CASTRO, Eduardo. Os pronomes cosmológicos e o perspectivismo ameríndio. MANA 2(2):115-144, 1996.

Lévi-Strauss nos 90 a antropologia de cabeça para baixo. Mana, Rio de Janeiro, v. 4, n. 2, p. 119-126, Oct. 1998.

Recebido em: 29/08/2020 * Aprovado em: 30/11/2020 * Publicado em: 16/12/2020 